\title{
Nurturing a Community of Practice through a Collaborative Design of Lesson Plans on a Wiki System
}

\author{
Atara Shriki \\ Oranim- Academic College of \\ Education, Tivon, Israel
}

shriki@technion.ac.il

\author{
Nitsa Movshovitz-Hadar \\ Technion- Israel Institute of \\ Technology, Haifa, Israel
}

nitsa@technion.ac.il

\begin{abstract}
Eleven graduate students, experienced mathematics teachers, participated in a semester long activity in which they collaboratively designed and developed lesson plans on a Media Wiki system. The described study examined the processes involved in this collaborative effort and its contribution to the development of mathematics teachers' community of practice. Data were collected through tracking each Wiki page written by the participants, their reflective journals, a questionnaire, semi-structured interviews, and researchers' notes of the whole class discussions.

Evidently, the use of the Wiki system triggered a process of change, and the participants quickly evolved into a small and very Wiki-active community of practice. The results indicate that this teachers' community of practice was concerned with two major issues: social ones and technical ones. The social issues related to the teachers' consideration as to how to provide and receive feedback, as well as uncertainty about the possibility of losing the ownership over their creative work. The technical issues had to do with various difficulties participating teachers faced while writing in Wiki syntax.
\end{abstract}

Keywords: Mathematics education, lesson plans, Teachers' community of practice, Wiki system.

\section{Introduction}

In Israel, a secondary school mathematics teacher has to prepare for about 20 lessons every week. As each school year lasts for about 30 weeks, it implies that these teachers have to prepare for about 600 lessons a year. Even if the teacher re-teaches the same topic over and again, it is usually not a mere repetition as revisit of the lesson plan usually takes place, adapting it to the current class in view of previous implementation.

Material published as part of this publication, either on-line or in print, is copyrighted by the Informing Science Institute. Permission to make digital or paper copy of part or all of these works for personal or classroom use is granted without fee provided that the copies are not made or distributed for profit or commercial advantage AND that copies 1) bear this notice in full and 2) give the full citation on the first page. It is permissible to abstract these works so long as credit is given. To copy in all other cases or to republish or to post on a server or to redistribute to lists requires specific permission and payment of a fee. Contact Publisher@InformingScience.org to request redistribution permission.
Because in Israel the mathematics curriculum is a national one, the very same topic is taught in hundreds of mathematics classes around the country every week (in small variances, of course). Unfortunately, the educational system does not offer teachers means for sharing the preparation or mechanisms for providing feedback following the implementation. As a result, teachers sel-

\section{Editor: Alex Koohang}

An earlier, shorter version of this paper was presented at the Chais conference 2011, in Raanana, Israel, and included in Y. Eshet-Alkalai, A. Caspi, S. Eden, N. Geri, \& Y. Yair (Eds.), Proceedings of the Chais conference on instructional technologies research 2011: Learning in the technological era. Raanana: The Open University of Israel. http://www.openu.ac.il/research center/chais2011/papers.html 
dom share their knowledge and practical experience with their colleagues. If done, it is usually limited to an oral discussion with few peers, without keeping records. Consequently, teachers usually keep re-teaching a topic in another class or in another year in quite the same way they did it previously, reflecting merely on their own experience. Needless to say there is hardly any preservation of accumulated professional knowledge for the sake of the community.

The rapid development of the internet and particularly the increasing use of Wikipedia inspired us to consider a Wiki system as a suitable platform for preserving, accumulating, and continuously improving mathematics teachers' practical knowledge, through collaborative efforts, aiming at empowering the mathematics teachers' community of practice. Thus, the goal of the present study was to examine a process of collaborative efforts to create practical knowledge.

\section{Literature Background}

\section{The Practice of Teaching and Community of Practice}

It is widely agreed that the critical factor in successful implementation of changes in the education system is the teachers' professional level, in particular teachers' flexibility and ability to translate innovative ideas into practice (e.g., Borko, 2004; Day \& Leitch, 2007). However, by its very nature teaching is a complex practice, as teachers should possess pedagogical content knowledge (Shulman, 1987), as well as knowledge of learning theories, teenage psychology, classroom management, and more. Specifically to the teaching of mathematics, Hill, Rowan, \& Ball (2005) refer to the need of having mathematical knowledge for teaching, which means "mathematical knowledge used to carry out the work of teaching mathematics", including "explaining terms and concepts to students, interpreting students' statements and solutions, judging and correcting textbook treatments of particular topics, using representations accurately in the classroom, and providing students with examples of mathematical concepts, algorithms, or proofs" (p. 373). In designing lesson plans, teachers should consider and integrate all these types of knowledge.

Despite the complexity of the profession, usually, teachers work in isolation. They work in separate classrooms with separate students, teach separate lessons, and are often completely unaware of what their peers do (Carroll et al., 2003). They make their own advanced planning decisions and solve on their own pedagogical problems that rise on the spot in their classes, with limited consultation and feedback from their colleagues. When collaboration does occur, it is usually restricted to an exchange of daily pedagogical anecdotes (Burbank \& Kauchak, 2003), and therefore "as a profession, teaching is often described as highly individualistic" (p. 500).

The past decade has seen increasing demand to improve school mathematics (e.g., the NCTM Standards, in the USA (National Council of Teachers of Mathematics, 2000); the National Strategy Standards, in England (Department for Education, 2011); The Education Reform Agenda, in Australia (Department of Education, Employment and Workplace Relations, 2011); Goals for the 2009/10-2011/12 School Years, in Israel (Pass, 2009)). This demand generated a need for teachers to join forces and share knowledge possessed by individuals in their community so as to develop common knowledge that can assist them in coping with the implementation of innovative programs (Coakes \& Smith, 2007).

According to Geoffrey (2008), the most obvious strategy for managing shared knowledge would be nurturing communities of practice. 'Community of Practice' (CoP) as a concept was coined by Lave and Wenger (1991) while studying apprenticeship as a model for learning a profession. CoPs are formed by people who engage in a process of collective learning in a shared domain of human endeavor (Wenger, 1998). These groups of people share a concern or a passion for something they do and learn how to do it better as they interact with one another on a regular basis. 
Thus becoming a professional is not seen as an individual acquisition of knowledge, but rather as a process of social participation in a learning community. According to Wegner (1998), in order for a community to be recognized as a $\mathrm{CoP}$, a combination of three characteristics, which are cultivated in parallel, is necessary:

(i) The domain: A CoP is identified by a common domain of interest.

(ii) The community: A CoP consists of members who are engaged in joint activities and discussions, help each other, share information, and build relationships that enable them to learn from one other. They do not, however, necessarily work together on a daily basis.

(iii) The practice: Members of a $\mathrm{CoP}$ are practitioners. They develop a shared repertoire of resources, such as experiences, stories, tools, and ways of addressing recurring problems, thus learn with and from each other.

CoPs develop their practice through a variety of activities, among them are documenting projects and ideas, assisting each other in finding information, sharing resources, discussing developments, solving professional problems collectively, and mapping knowledge.

In general, national communities of mathematics teachers conform to Wegner's first two characteristics: they definitely share an interest in mathematics, its teaching and learning, and in many countries they meet in professional conferences, read professional journals, and share a professional jargon enabling them to learn from one another (Hislop, 2002; Romberg, 1988). However, the third characteristic, to a large extent, is still missing in many national communities of mathematics teachers. Although a vast majority of them are practitioners who teach mathematics on a regular basis, only few develop a shared repertoire of resources, such as experiences, stories, tools, and ways of addressing recurring problems. Even those national communities of mathematics teachers who do develop such resources, usually count on leaders of the community to put them together for the benefit of the entire community.

Our initiative was aimed at making an initial step towards improving this third characteristic of the mathematics teachers' CoP, relying on the significant amount of professional knowledge and experience possessed by individual members of the community- the ordinary mathematics teachers. This was done through employing a standard Wiki system for sharing their daily teaching plans and their gained experiences from implementing these plans, on the one hand, and for collaboratively improving lesson plans for future implementation and accumulating a documented repository, on the other hand. The study examined the virtue of the Wiki-based collaboration and its shortcomings towards this aim.

\section{Wiki System and Its Use in Education}

\section{Wiki system}

In 1995 Ward Cunningham developed the idea of Wiki, believing he had created the simplest online database that could possibly work. For his server software idea Cunningham had chosen the Hawaiian word "Wiki-Wiki", which means "quick". As such, Wikis provide a means for open, worldwide collaboration on all kinds of topics (Delgadillo, 2004). The truly revolutionary feature of Wikis is their openness for editing by numerous people. While most websites are secured from editing, Wikis allow anyone to modify and elaborate contents. Therefore, in contrast to traditional websites, every reader is also a potential writer (Foley \& Chang, 2006).

Wiki serves as a collaborative tool that facilitates the production of group work for building dynamic knowledge bases. It is characterized by a 'browser-based access', which means that neither special software nor moderator webmaster is needed to post content (Ebersbach, Glaser, \& Heigl, 2006; Schwartz, Clark, Cossarin \& Rudolph, 2004). Page contents can be directly linked to those 
found in other Wikis (interWiki) and in other web documents. Wiki pages can be interconnected and organized as required and are not presented by default in a reverse-chronological, taxonomichierarchical, or any other predetermined order. Besides open editing, the uniqueness of Wikis lies in their relatively simple text formatting language, the storage of earlier versions in online database, the equal user role, the collaborative nature of the pages, and the ongoing process of their development (Arreguin, 2004). These make Wikis highly flexible knowledge management space and, consequently, a very effective way for building and exchanging information through collaborative efforts (Duffy \& Bruns, 2006).

Although Wikis bear a collaborative nature, Wiki pages evolve into a coherent, well thought out body of knowledge (Arreguin, 2004). While open editing may sound chaotic, experience shows that even though individuals can post purposely factually incorrect information, it is rarely the case, mainly because the Wiki concept is based on mutual trust and common sense. Therefore, some rules of etiquette are agreed upon and kept when contributing to Wiki entries. Among these rules are the consideration of the target readers and the preservation of the contributions of others. Indeed, the majority of users follow the 'Wiki etiquette' (Delgadillo, 2004). Nevertheless, given that each time a page is edited, a copy of the previous version is saved, it is possible to track the changes of individual pages over time, and the users are able to browse and view the developmental history of each page (Duffy \& Bruns, 2006). Therefore, even in cases of intentionally destructive editing, it is easy to replace the damaged version with an earlier one, and hence the lifespan of an error is relatively short.

\section{Using Wiki for educational purposes}

The rapid development of digital technologies and their use in education enable individuals to interact within the educational domain in new learning environments, one of which is the Wiki environment. As a socially based technology, Wiki corresponds to pedagogical theories that view learning as a socially constructed engagement (Duffy \& Bruns, 2006).

Wikipedia became one of the best known implementation of the ideas underlying Wiki. According to Wikipedia itself, since its creation in 2001, it has grown rapidly into one of the largest reference web sites, attracting around 78 million visitors monthly as of January 2010, and around 400 million visitors monthly as of March 2011 ("Wikipedia:About," n.d.). Being recognized as a trustworthy and a valuable information resource-base for educational purposes, Wikipedia had inspired a growing interest in the educational uses of Wiki systems for various educational purposes.

At the simplest level, a Wiki page can be a useful tool for instructors to present information. It may also be a powerful tool for students at various levels. Individual students can post their works; groups of students can collaborate on carrying out assignments or creating a knowledge base and can also post their arguments, ideas, and questions (Foley \& Chang, 2006). By creating a tangible representation of knowledge, Wikis support the development of teacher-learners communities and the generation of websites which are social construction of knowledge (GoodwinJones, 2003). Prospective teachers can also benefit from utilizing Wiki for discussing pedagogical principles and ideas (Foley \& Chang, 2006).

In higher education Wiki can be employed successfully for sharing knowledge (Konja \& BenZvi, 2008a, 2008b), encouraging collaboration among students (Tal \& Tal, 2006), supporting inquiry learning (Levin- Peled \& Kali, 2008), supporting peer instruction (Levin- Peled \& Kali, 2009), promoting mathematics discourse (Cohen, 2009), and it can also serve as an ideal platform for distance learning (Tal-Elhasid \& Meishar-Tal, 2007). 


\section{Wiki and nurturing a community of practice}

The accumulation over time of knowledge and expertise of specific domain distinguishes CoPs from other communities that share their interest and knowledge through the internet (Wenger, 2001). Due to the inherent characteristics of Wikis, members of any CoP can develop its shared content-world and practice by interacting around common problems and negotiating solutions and insights. Consequently, Wikis can serve as an ideal environment for the development of a CoP, through creating a collective repository of expertise in the CoP's area of interest, which is refined over time by the contributions of interested individuals (Godwin-Jones, 2003), and co-editing of documents from a distance (Eshet-Alkalai, 2004).

Although not developed specifically for education, Wiki technology has features that can be particularly helpful for teachers CoPs (Foley \& Chang, 2006). Wikis can be used as a knowledge base for teachers, enabling them to share knowledge of the subject matter they specialize in, to reflect and share thoughts regarding lesson plans, teaching practices, pedagogical ideas, and more (Duffy \& Bruns, 2006), thus enabling teachers to engage in the complexity of teaching (Barab, Makinster, Moore, Cunningham, et al., 2001).

\section{Implications to our study}

Human societies face cognitive tasks that are beyond the capability of any individual member, and, therefore, fostering collective cognition can be beneficial to solving problems that are too complex or demanding for an individual (Lund \& Smørdal, 2006). Such perception is fundamentally valid in the context of education, in general, and in the context of teachers' CoP, in particular. The process of generating collective knowledge has a social component. It is widely recognized that the majority of innovations in organizations emerge as a result of collaboration among people who exchange thoughts and ideas (Curry, Sherry, \& Tunney, 2003). This social component enhances the usefulness of a tool such as Wiki, which provides the opportunity for constant contacts, on-going discussions, and rapid feedback (Köhler \& Fuchs-Kittowski, 2005). Practical knowledge that collaboratively accumulates on a Wiki system quickly turns into a reliable source of information due to the fact that its generation and development are carried out through a process of peer review. In such process, the participants have similar background, and while providing mutual feedback they collectively improve the products (Herndon, 2006). Since each member is capable of observing strengths and weaknesses of some particular products, as a group they have the power of recognizing a large variety of weak points (Rogers \& Threatt, 2000). Furthermore, in most cases, the group of contributors develops and edits the Wiki pages on a basis of mutual interest, with the aim of generating an improved product (Keig \& Waggoner, 1994). Therefore, they are motivated to take a personal ownership in ensuring the accuracy of the discussed topic through a peer assessment process and to avoid intentional harm (Herndon, 2006).

Considering the above, we thought that Wiki system might be effective in supporting the development mathematics teachers' CoP.

\section{The Study}

In this section, we describe the aims of our study, the subjects, the phases of constructing the repository of mathematics lesson plans on a Wiki system, the methodology and research tools, and the methods used for analyzing the data. 


\section{The Goal of the Study}

The goal of the current study was to characterize:

(i) The processes involved in a collaborative effort of mathematics teachers to design lesson plans, and gradually build a Wiki system based repository;

(ii) The contribution of this effort to the development of mathematics teachers' community of practice.

\section{Participants}

Eleven mathematics teachers, having the average of 17 years of mathematics teaching experience, participated in the study. All of them were M.Ed. students in a large college in northern Israel. Three of the teachers teach mathematics in junior high school, 6 in senior high school, and 2 in both. Their participation in the study was a mandatory part of the program.

\section{The Development of Lesson Plans Repository}

\section{The platform}

A large number of Wiki systems have been produced. Some of the more popular Wiki systems include MediaWiki (www.mediawiki.org), which is a free software open source Wiki package written in PHP, originally for use on Wikipedia. The MediaWiki system provides several features valuable for teachers, particularly a number of ways to look at the history of a page and the total edits made by an individual user (Foley \& Chang, 2006).

The development of the lesson plans repository took place on a MediaWiki site that was established specifically for the study. Its Main page included technical support for using the system, as will be elaborated in the next section.

\section{Phases of work}

Prior to the beginning of the study, the participants received from a Wiki expert a 2-hour preparatory, in which he taught them how to use the MediaWiki site - create their own account, compose a page, write, edit, upload files, create links, use the discussion tab, view the history page, and more - as they had no previous experience with Wiki, except from being passive end-users of Wikipedia.

The development of the Wiki repository took three months in four main phases:

Phase 1 (two weeks). Individual work - generating personal Wiki pages entitled "My statement of belief": Each participant had to elaborate on what constitutes in his or her view a good mathematics lesson: meaning, essence, structure, and more.

Phase 2 (three weeks). Small groups work - consolidating guidelines for producing "a good mathematics lesson plan": Participants were randomly assigned into small groups of 2-3 members. Each group member had to comment (using the discussion tab) and/or edit directly his or her group peers' Wiki page and in this way generate collaboratively a new Wiki page that reflects (i) the agreed-upon group-perception regarding "a good mathematics lesson plan" and (ii) specific guidelines for designing and evaluating such lesson plan.

Phase 3 (three weeks). Individual work - generating one mathematics lesson plan, following the guidelines that were consolidated in Phase 2. 
Phase 4 (five weeks). Small groups work - collaborative modification to improve the design of group members' lesson plans generated in Phase 3: Participants were grouped based on the grade levels they teach and curricular-topics expertise. In this phase they had to comment and/or edit their group peers' lesson plan and to improve his or her own lesson plan following comments and suggestions from the group. They were also free to edit or comment on lesson plans of participants not in their group.

During the entire process the participants were provided with a daily technical support from the Wiki expert. He responded to each one personally several times a day through the "notice board"a page that was initiated by the participants, in which they discussed technical issues, shared their successes and difficulties, and advised each other. Occasionally, as needs arose, he also uploaded to the Main page of the site videos he had produced, directing the participants as to handling the work and overcoming specific technical problems.

A whole class discussion was held by one researcher at the end of each of the three first phases, and weekly during the fourth phase, focusing on participants' experience and insights. The researchers took notes of these discussions.

It should be noted that participants were not provided with any particular instructions as to making comment, editing, or working collaboratively. In addition, the researchers did not initiate any interference throughout the 4 phases of the participants' individual or group work, except for cases in which a participant explicitly asked for advice. We deliberately excluded ourselves from the process in order to avoid imposing our own views and in order to allow for a CoP to possibly evolve in an environment that is as autonomous as possible.

\section{Methodology}

The study was conducted following the mixed-methods approach (quantitative as well as qualitative). Studies using mixed-methods approach have shown that integration of these methods have the potential to increase the quality of the analysis, and to provide a more comprehensive understanding of processes involved in the study (Caracelli \& Greene, 1997).

The data were gathered from:

(i) The Wiki pages, the histories of their development, and statistical information regarding the actions that were performed in creating the pages.

(ii) Participants' reflective journals. The participants were asked to write journals on a regular basis, describing their experience and thoughts and reflecting on them. They were also asked to reflect on their entire experience by the end of the process. The participants had to send the researchers a copy of their journal by e-mail at least once a week. Each e-mail was answered immediately in order to maintain motivation. Our feedback, however, was not judgmental. We mainly asked for further clarifications and elaborations and suggested our advice when it was asked for.

(iii) A questionnaire. At the end of the four-phase process, the participants were asked to respond to a questionnaire about various aspects related to their engagement with the Wiki system, their social interaction, and the Wiki as a media for nurturing a CoP. The questionnaire was not anonymous to enable cross-checking of information about the professional development of each participant.

(iv) Personal interviews. During a month after the administration of the questionnaire, all 11 participants were scheduled for a personal interview. Each interview lasted for about 30 minutes and took place in a quiet room in the college. The aim was to deepen our understanding of the processes involved in the development of mathematics teachers' CoP 
through their engagement in collaborative effort to design lesson plans on a Wiki system. The interviews were recorded and then transcribed.

(v) Researchers' notes of the whole class discussions.

\section{Methods of analysis}

The reflective journals, the questionnaire, the personal interviews, and researchers' notes were analyzed through analytic induction (Goetz \& LeCompte, 1984), reviewing the entire corpus of data to identify themes and patterns and generate initial assertions regarding the focal points of the study.

The textual information of the Wiki pages was analyzed through content analysis (Neuendorf, 2002), in order to generate categories that characterize the development of collective knowledge.

The technical operations that were conducted by the participants were analyzed using basic statistical tools.

\section{Results and Discussion}

We first present some statistical data about the operations that were performed in the site, followed by findings related to the manner in which the use of Wiki was perceived. We then move to a discussion of the main issues related to participants' involvement in the collaborative design of mathematics lesson plans, as they emerged from the qualitative data. Due to space limitation, this paper presents only the analysis of qualitative data gathered through the participants' final reflection on their entire experience and the transcripts of the interviews, focusing only on those issues that emerged most prominently in the process of analyzing the data.

\section{Participants' Presence in the Site}

An intensive presence of the participants in the site was recorded during the period of three months in which the study went on: 219 pages were generated in the collaborative repository, including content pages, discussion pages, and support pages, and 95 files were uploaded; 8,554 observations were carried out, and 1,268 editing operations were performed. On the average, each page was edited 5.79 times, and viewed 6.75 times. The Main page (in which the Wiki-support was provided) was the most observed (1035 times), and then the "notice board"- a page that was initiated by the participants, in which they discussed technical issues, shared their successes and difficulties, and advised each other (490 times). Lesson plan pages were viewed 154 times each, on the average.

\section{Participants' Perceptions about the Wiki System}

The following advantages and disadvantages of the Wiki system they used were mentioned by four or more participants in their final reflection (we did not include those who were mentioned by less than four):

Main advantages:

- The simplicity of managing information on Wiki system: no need to download/upload files, open and save files, and send files to recipients (as opposed to file management systems) (11 participants);

- The effortless ability to trace the history and evolution of each Wiki page and to identify its contributors ( 9 participants); 
- The option to observe and edit pages or post a comment at any convenient time and place, according to one's preferences. This is as opposed to the need to reach one another by phone, or coordinate schedules when a collaborative group work is done in a face-toface mode (8 participants).

Main disadvantages:

- The need to upload mathematical formulas, tables, diagrams, and figures, which cannot be inserted directly through a Wiki editor, causes spending time on matters that should not be time consuming ( 9 participants);

- The need to remember a lot of technical information: the Wiki language of editing, how to change the name of a page, how to transfer information from one page to another, how to restore edited pages, and more (8 participants);

- Inability to save a lesson plan in a 'draft' format, to enable to 'hide' it temporarily until its completion (4 participants).

It should be noted that only the first disadvantage mentioned above is specific to the collaborative design of mathematics lesson plans. The rest of the points can be found in other studies (e.g. Da Lio, Fraboni, \& Leo, 2005; Elgort, Smith \& Toland, 2008).

Furthermore, the majority $(9 / 11)$ of the participants explicitly stated that unless they had received a constant technical support, they probably would not have been able to produce a product of the high quality they felt they had obtained. The fact that they received a daily response to their questions and difficulties from the Wiki expert enabled them to work persistently on their assignment.

As with any novel technology, the use of Wiki in education presents teachers with new difficulties and challenges (Wheeler, Yeomans, \& Wheeler, 2008). Although the participants in this study acknowledged the Wiki system as a useful tool for the tasks they performed, they also faced several difficulties associated with their operating within an unfamiliar technological environment. The major benefits acknowledged were the simplicity of managing information and tracing the history of each Wiki-page and the ability to interact with their peers in an asynchronic fashion. However, some technological barriers put obstacles on participants' road to successful performance of the tasks assigned to them, among them, the need to remember quite a bit of technical information including a new syntax and the additional burden caused by the limited features of the MediaWiki editor, which requires uploading mathematical formulas, tables, diagrams, and figures rather than inserting them.

Obviously, teachers need to be pre-trained before delving into Wiki-based environments, otherwise the effectiveness of Wiki system as a collaborative tool that supports the development of teachers' CoP might be low. However, our study indicates that pre-training in itself is insufficient, because during the process, as teachers' involvement with the Wiki system becomes deeper, new technical problems often arise. Therefore, it appears that the development of a Wiki-based repository requires a constantly accessible technical support, or else teachers' $\mathrm{CoP}$ members might not stay actively involved in contributing to the growing repository. In addition, in the particular case of mathematics teachers' CoP, as it was evident that MediaWiki was not sufficiently friendly for posting and editing mathematical information, it is necessary to identify an alternative Wiki system or adapt the MediaWiki to the specific needs of mathematics writing and editing.

\section{Participants' Perceptions on the formation of a Teachers' CoP}

During the interview, participants were asked to relate to the question whether the collaborative work on the Wiki system contributed to the formation of their mathematics teachers' CoP. Without exception, all of them asserted in one way or another that a teachers' CoP was developed as a 
result of their experiences and changed their usual state of professional isolation that characterizes their daily work (quotations are in Italic. All the quotations were originally stated in Hebrew).

Typically, participants asserted that "...it was the first time I had the opportunity to discuss various pedagogical ideas with colleagues. I believe this is what a community is all about". In fact, as they believe, "...this is how a community of teachers should conduct itself-every teacher feels free to present his approach, and others can learn from it and comment about it. I learnt so many things in a relatively short time". In addition to learning from each other, exchanging of ideas "...gave me the feeling that I was not alone. I could consult my friends, and they consulted me. I could see what they did, and they could see what I did. It was a great feeling".

When asked to relate to the unique contribution of the Wiki system towards the development of teachers' CoP, participants' replies referred to the repository of lesson plans itself, to the ability to consult each other, and to the convenience of communicating in an asynchronic manner: "...many times I wanted to ask the teachers in my school questions like how to solve a certain question or what is the best way to teach a certain topic. But for some reason we don't ask each other such questions. Perhaps we don't want to appear as helpless. But with Wiki it is different. Because Wi$k i$ and collaboration are synonyms, you can be sure that you are not going to be the only one who asks questions, so you just ask". Beyond the fact that the Wiki encourages teachers to ask for help, the ability to ask it in any preferable time and place turns Wiki into an efficient media for that purpose, since it provides time to think of appropriate response: "The wonderful thing about Wiki is the fact that as a community we don't have to meet each other. It enables one to think about things, and relate to them when one is ready and has time. When you meet face-to-face with other teachers, you have to react immediately. This is not always for the better. You don't have enough time to think, and you might say things you did not really intend to. In addition, the fact that things are written, enables you to return to them whenever you like. It is not the same when things are said orally, and you forget them pretty fast".

The participants were surprised to realize that Wiki enables them to receive a variety of responses: "It enabled me to consult with the entire group, and receive advices from all of them. This was amazing. Two hours after I posted my dilemma, I received three different opinions. It couldn't happen without the Wiki". In addition to discussing pedagogical dilemmas, the participants were also enriched by teaching ideas and approaches: "The Wiki enabled us to share our lesson plans, and observe those of others'. Together we produced a rich and varied repository, and I am going to try some of them in my class". Moreover, "...the fact that I can roll back the history of each lesson plan, and observe several versions of it, is a great thing. It enables me to choose the most suitable version for my class". In conclusion: "...Wiki looks like the ultimate way to collaborate in designing lesson plans. Every participant could add his ideas, everyone could easily relate to these ideas, and together achieve an improved product";

Although most participants mentioned they received quick responses to pedagogical dilemmas they posted, this was not always the case when they wrote a lesson plan. Believing that a quick response is essential for the development of a CoP that communicates through Wiki, two participants noted, "The idea of Wiki as a platform for a community of teachers is great. However, there were times I felt that it was only me and the Wiki. I made efforts to respond and comment as quickly as I could, but not all my group members did so as well. I think a community cannot exist, unless everyone has the same sense of commitment". It might be that some participants had overexpectation: "After I posted my lesson plan, I was eager to see what others have to say about it. I was disappointed when I did not get any echo soon afterwards, although I always commented and edited my group members' lesson plans soon after they posted them". Directing her comment to the interviewer she added, "As the initiator of this Wiki, you have to think about this, because you might discover that the community is not evolving as you would like, just because not everyone 
feels committed to the community". These two reactions imply that working collaboratively on Wiki system might generate unreal expectation as for the pace of reaction time. This missed expectation might prevent some teacher from actively participate in the CoP, thus further research should examine this issue more deeply.

Examining the results and referring to Wenger's definition of $\mathrm{CoP}$, it is evident that these 11 teachers gradually turned into a (relatively small) active teachers' CoP: (i) The domain - to start with, they had a common domain of interest, namely high school mathematics teaching; (ii) The community - they were engaged in joint activities and discussions in the form of the assignments we gave; (iii) The practice - they were all practitioners and during the study they shared their resources, and learned with and from each other. The contribution of the Wiki system to evolvement of this CoP is apparent. Firstly, it provided the teachers a sense of belonging. They felt that they were no more isolated, and could openly consult their peers and learn from them in any time. Secondly, they were exposed to and enriched by various pedagogical ideas and lesson plans, and collaboratively improved them through the unique architecture of the Wiki system.

Nonetheless, in order to ensure the gradual development of teachers' $\mathrm{CoP}$ and encourage a productive asynchronic follow-up discussion after giving or receiving feedback, there is a need to identify ways to instill a sense of commitment to potential members of the CoP.

\section{Participants' Perceptions about Giving and Receiving Feedback}

Although the participants are used to providing feedback to their students, this was their first experience with providing feedback to colleagues. They approved of giving and receiving feedback as inherent components of any collaborative work: "...feedback is at the heart of any professional discourse".

As perceived by the participants, feedback is useless unless "the community members exhibit openness and readiness for making changes", which in turn "will improve the professional work of each individual in the group". In general, the Wiki system was acknowledged as a useful media "for initiating a productive discussion" and "developing awareness of the central role played by a culture of discourse as a means for improving lesson plans". What turned the Wiki system website into a powerful means to this end, they claimed, was the fact that "one can consider, in his/her free time, what and how to comment on peers' work and how to respond to received comments". In addition, "...since everyone was able to see about what and how others made their comments, and about what and how recipients reacted, one could gather from all these what might be considered as 'politically correct' for our community".

Relating to the difficulties associated with giving and receiving feedback, all the participants distinguished between feedback to posted pedagogical dilemmas and feedback to lesson plans. In their final reflection, most of their reference to these issues concerned with the latter.

\section{Providing feedback}

Giving feedback to peers was the issue that the participants were most concerned about, mainly due to their "lack of previous experience with providing feedback to colleagues". Seven of them asserted that it was much easier to receive feedback than to give it, because "the recipient might get hurt, or perhaps think that I have something personal against him or her". Most of the participants argued that "since we are not used to give feedback to our peers, it was impossible to anticipate the reaction of the recipient", and it might be that "the recipient will not be so happy about my feedback". As a result, at the initial phases of the process, they often found themselves "avoiding from making comments" just because they had "no idea how to phrase it in a 'politically correct' manner". 
In general, all the participants believed that "...the manner in which words are phrased is no less important than the words themselves". Therefore, they paid a lot of attention to the selection of appropriate wording for their feedback: "If you wish the recipient to consider what you say, the comments should not be phrased in a judgmental manner". Furthermore, "...I always tried to write something like 'you might consider changing this to that', and never wrote 'you are wrong, you should have written it like this"'. Five of them maintained that they did not want "to be portrayed as patronizing". In other words, they were concerned that "the recipient of a feedback might interpret it as arrogance". Nonetheless, "criticizing is unavoidable if we wish to build ourselves as a community. It is true that we have to be careful with words, but the Wiki website would be useless without commenting to each other".

Another issue concerning provision of feedback was whether it should be in the form of direct editing of the content pages or in the form of comments and suggestions in the discussion pages.

Eight participants supported the idea of providing feedback merely in the discussion pages. Their main arguments related to respecting others, keeping one's privacy, and faithful collegiality: " $A$ page is the 'private zone' of the author, and I don't think I have the right to violate the privacy", and in fact, "...indirect intervention respects the rights of the author". Therefore, "...it is better to let the author of a page to decide whether or not to change it after considering the comments received. After all, this is his/her page". Furthermore, "...not editing one's work or intervening in it, is an act of collegiality". Moreover, 4 of these 8 participants believed that commenting in the discussion page is more efficient, because it enables one to explain and express ideas more clearly: "When you edit someone's page, it might be that the author will not understand why you have changed things. If you comment in the discussion page, you can explain the reasons for the suggested changes". Relating to social aspects, two participants thought that "a direct editing might damage any relationship between the two teachers", and three claimed that "since we all know each other I felt unease to edit others' lesson plans", because "someone might have taken it personally". Additionally, 2 of the 8 participants who supported comments rather than direct editing felt that "even writing comments in the discussion page might be problematic, because the rest of the group is able to read it, thus violating the privacy of the teacher who created the Wiki page".

On the other hand, three of the 11 participants were in favor of direct editing, maintaining that this was the only way to advance and develop the final product, to improve its quality, and to achieve these goals as rapidly as possible: "Editing is the only way to ensure that as a group we will reach the highest qualitative product"; "We could have completed the design of the lesson plans much more quickly if instead of just commenting, everyone would have done the editing straightforward". In addition, "direct editing is what Wiki actually about, otherwise we could just exchange files with 'track changes"', and "we have to dare and edit the lesson plans. Wiki is about collaborative work and collaboration means that we all share these lesson plans".

Viewing the issue of feedback as central to the development of a $\mathrm{CoP}$ and in order to avoid ongoing debates regarding how to provide it, 4 participants suggested that "if we wish to avoid indecisions regarding whether to edit the lesson plans or respond in the discussion page, it is highly important to agree in advance about how to give feedback". In other words, "the group should pre-determine what is acceptable and what is not, in order to eliminate personal doubts regarding how to comment to one another's work". In addition, mutual consent about the right to edit the lesson plans "...might prevent people from being insulted just because someone edited their lesson plans against their will".

\section{Receiving feedback}

The issue of receiving feedback from peers also gained a lot of attention. All the participants referred to the importance of receiving comments to their lesson plans and said that their peers' 
feedback assisted them to reflect on their own lesson plan and improve it. All the participants also mentioned that their peers' comments were practical and useful, and that it was evident that they were intended to help: "I really loved the comments to my lesson plan. It improved it and added a fresh point of view". In addition, "...the feedbacks I received were very useful. They helped me understand in which parts of the lesson plan I was clear, and in which parts I have to explain myself better". Relating to their peers' intentions, they felt that "...it was apparent from the way others commented that they really wanted to help me improve my lesson plan. They really gave it a thought".

As in the case of providing feedback, there were also different opinions regarding the mode of receiving feedback. Seven participants explicitly supported the option of direct editing of their lesson plan, believing that it enables to achieve a better product: "At the beginning we just commented to each other in the discussion page, but then we realized that it was not efficient. We started to directly edit the lesson plans, and we used the discussion page only as a supplementary. We both agreed that the final product highly improved as a result of this procedure". Support in the direct editing was also driven by the participants' wish not to be portrayed as arrogant: "I don't think I know more than the others. I am not superior to them. It might sound bad if I would prevent them from editing my lesson plan". However, two of those who supported direct editing admitted that "if as a result of the editing my lesson plan was totally different from what I initially had meant, I am not sure I would be so happy about it". Two other participants assumed that "if it was a mathematical Wiki page, and not a personal lesson plan, I believe it would be much easier for others, emotionally, to edit it".

Only one participant explicitly objected a direct editing of her lesson plan, maintaining that "those who are not familiar with the learning environment in which I teach cannot suggest suitable changes. One should first tell me his/her suggestions, and I will consider it... Often there are several legitimate ways to introduce a topic, and there is no clear way to identify a 'better' approach".

\section{An observed gap}

There is a noticeable gap between participants' self-perception as providers of feedback and as feedback recipients. As recipients of feedback in general they accepted it as a constructive criticism and acknowledged it as helpful, while as providers of feedback they were quite hesitant, afraid that it might be interpreted as arrogant, patronizing, or even destructive criticism.

Similarly, from the above quotations one can observe a gap between participants' reflections on their own gain from their peers' feedback, as opposed to their refrain from explicitly mentioning the contribution of their feedback to improving others' lesson plans.

The origins of these gaps are not easy to explain. Clearly for a well functioning CoP to develop, bridging these gaps is desired. There is a need for further research to examine the underlying reasons for these gaps and how to manage them.

\section{Participants' Sense of Ownership over a Product}

The collaborative design of lesson plans raised a debate regarding ownership and copyrights, as was evident from participants' final reflection. Six of the participants considered the possibility of viewing the history of every page and identifying the unique contribution of each participant to the collective product as highly important: "This guarantees that everyone would be able to acknowledge who initiated a page and who contributed to its development, and what was the essence of the contribution". Among these 6 participants, 2 maintained that it was hard for them to accept that "everyone can use my lesson plan without asking for my permission and without informing others that it was mine". Three of these 6 participants claimed that "although the possi- 
bility of tracking the history of each page is important, it is not sufficient", because "anyway, no one will bother to track the contributor of every change". Furthermore, these participants claimed that "there should be another mechanism that enables to highlight the names of contributors to each page".

Contrary to these 6 participants, 2 participants asserted that keeping ownership and copyrights were unnecessary and that "people should acknowledge the fact that in Wiki, things are the property of everyone, therefore can be used freely, as one wishes". Moreover, "in the Wiki era teachers should give up their ego and privacy, and acknowledge that what they get in return exceeds the loss". In their opinion, and "those who are unable to give up their copyrights, actually have difficulties in giving up their pride. They should realize that the Internet forces people to leave their pride behind".

In the context of this study, all the participants were obliged to share their lesson plans with one another. The idea of modifying and editing their documents by others brought up some resistance towards the idea of losing the ownership over their products, and even a frustration. Considering the ownership issue as related to Wiki systems, one should be aware of the basic distinction between an encyclopedic repository such as Wikipedia, which is essentially an expository writing of consensus-based reference work, and teachers' lesson plans repository, which is essentially a creative design work, experience-based, and personal. However, adhering to ownership over uploaded lesson plans may inhibit the process of their on-going improvement by the CoP's members.

In a wider future experiment, an effort must be made to make teachers acknowledge that 'the whole is greater than the sum of its parts', namely, the collective knowledge of a group is greater than that of the individuals, and that by giving up ownership and copyrights one gains more than one loses. One of the participants summarized it nicely: "As a community, each of us should acknowledge the fact that once a lesson plan is on the Wiki system, everyone is entitled to use it as he or she wishes. These lesson plans are a common property, and it doesn't really matter who generated them. This is not about ego and pride. This is about us, the community. No doubt it will be for the benefit of all". Indeed, participants who acknowledged that lesson plans on the Wiki system become a common knowledge, and once they are posted they are no longer private, expressed more readiness to make their lesson plan edited by others.

\section{Summary and Conclusions}

Nowadays, it is commonly agreed that one's acquisition of knowledge takes place mainly as a result of interaction and negotiations with other people (e.g., Wheeler et al., 2008). Teachers, however, generally work in isolation, with a limited collaboration with their colleagues (Burbank $\&$ Kauchak, 2003). This deprives them of acquiring and deepening their professional knowledge through sharing their experiences with their colleagues. Therefore, as teacher educators, we were looking for ways to promote teachers' collaborative work to generate and share their personal, professional and practical knowledge. In the Internet era with the increasing use of Wiki systems for educational purposes (Ebner \& Kickmeier-Rust, 2008), it was only natural for us to employ a Wiki system for this purpose. This is in accord with several studies published in the past few years that indicate that through co-editing of documents from a distance, Wiki systems enable the gradual accumulation of knowledge and expertise of CoPs through creating a collective repository of resources in the CoP's area of interest (e.g., Da Lio et al., 2005; Duffy \& Bruns, 2006; Eshet-Alkalai, 2004; Foley \& Chang, 2006; Godwin-Jones; 2003, "Horizon Report," 2007; Owen, Grant, Sayers, \& Facer, 2006; Wenger, 2001; Wheeler et al., 2008). Specifically to teachers' CoP, our goal was to employ Wiki system, as a social medium of web-based environment, to serve not only as a repository for various teaching resources, but also as a platform for sharing 
thoughts regarding lesson plans, teaching practices, and pedagogical ideas, as well as sharing problems and solving them together.

Evidently, the use of the Wiki system had triggered a process of change, and the 11 participants quickly evolved into a small and very Wiki-active CoP. This change was expressed in the way teachers were interacting, discussing, sharing ideas, and managing professional resources. With this regard the process was overall successful, and it is apparent that Wiki systems can serve as a valuable tool for nurturing teachers' $\mathrm{CoP}$.

Nevertheless, it was not the Wiki technology itself that was valuable, but rather the underlying Wiki philosophy and its interpretation by the participants. As noted by Da Lio et al. (2005) technologies do not fall into a social void. In fact, members of a CoP make use of technologies through the lens of their own social context and norms. Although the study participants faced several technical problems, these authors believe that most problems concerned with the usage of Wikis are rooted in sociological and psychological causes rather than technological ones and are mainly concerned with participants' resistance or inability to accept the Wiki philosophy. This philosophy is about free and democratic participation, ongoing collaborative updating, changing and editing, and conservation of page history (Kussmaul, Howe, \& Priest, 2006). However, as the literature review of Da Lio et al. (2005) indicates, most Wiki users do not adhere to the Wiki philosophy, and Burns \& Humphreys (2005) explain this phenomenon by various difficulties users have in assimilating and internalizing its social codes.

Indeed, in this study most participants' behavior was governed by their social norms. This was particularly noticeable in the manner in which they provided feedback and in their reaction to feedback they received, as well as in the importance they ascribed to the aspect of copyrights and ownership over of products.

Wrapping up, it appears that one necessary condition for achieving the goal of productive discourse and successful collaboration on a Wiki system is that teachers become acquainted with the concept of Wiki and its philosophy and accept it through developing new social norms. For that matter, teachers should acquire various types of skills that they do not commonly possess. For example, they should become skilled at collaborating with one another and evaluating each other's materials instead of working individually and independently on their lesson plans. They should be ready to consider inoffensively their colleagues' criticism and handle a peer discussion in order to reach a consensus; they should have the confidence required to express uncommon opinions and views; they should be able to comment and edit others' materials, or even delete parts, without fearing of hurting others' feelings. And above all, they should realize that "once the 'send' button has been pressed, the idea no longer belongs exclusively to the originator, but now becomes the property of the whole learning community" (Wheeler et al., 2008, p. 994). Taken all these together, hopefully teachers' CoPs will be able to collectively build an ever-growing repository of their practical knowledge, one that serves as the voice of the $\mathrm{CoP}$, and enable a meaningful change in education.

\section{Some Reservations}

This study was a preliminary one. Its participants were a small group of teachers who took part in the activities not because they had some expectations to benefit from them or were otherwise motivated. It was a required activity in the course of their graduate studies. Hence any generalization as to the willingness to get actively involved in developing collaboratively a repository of lesson plans, if offered to the entire mathematics teachers' CoP, is not obvious. Based on their experimental work, Ebnar \& Kickmeier-Rust (2008) hold the opposite to be true. According to these authors, "even in the most successful Wiki system [Wikipedia], only a very small number of users [2.5\%] are willing to spend time and make efforts to provide knowledge for other users" 
(p. 205). Clearly, the driving force behind an ever-growing lively Wiki, and in particular a Wiki that is supposed to serve a CoP, is the active involvement of the CoP's members as content generators. Future research should address motivational aspects that relate to teachers' readiness to contribute to Wikis on a voluntary basis.

In addition, the teachers who participated in the study knew each other, and part of their work was completed through face-to-face meetings. Obviously, this is not the reality in the wider mathematics teachers' CoP. Therefore, it is impossible to anticipate or characterize social processes and difficulties that might emerge while employing a similar process in the entire CoP. Examining the behavior of CoP members both as passive end-users and as active contributors, as well as characterizing the gradual development of a CoP, deserve a wide scale study.

To conclude our paper here is an optimistic vision of one of the participants: "I wish I could do 'fast forward' and see this Wiki five years ahead. I am sure it will be full of wonderful lesson plans created by a faithful community of mathematics teachers. Our lives as teachers are going to be much easier. Just write the topic in the search line, and get plenty of excellent ideas!"

\section{References}

AFT (American Federation of Teachers) (2002). Principles for professional development, AFT's guidelines for creating professional development programs that make a difference. American Federation of Teachers. Retrieved on August 2008 from: http://www.aft.org/pubsreports/downloads/teachers/PRINCIPLES.pdf

Arreguin, C. (2004). Wikis. In B. Hoffman (Ed.), Encyclopedia of educational technology. Retrieved from http://coe.sdsu.edu/EET/

Barab, S. A., Makinster, J. G., Moore, J. A., Cunningham, D. J., \& the ILF Design Team (2001). Designing and building an on-line community: The struggle to support sociability in the inquiry learning forum. Educational Technology, Research and Development, 49(4), 71-96.

Borko, H. (2004). Professional development and teacher learning: mapping the terrain. Educational Researcher, 33(8), 3-15.

Bruns, A., \& Humphreys, S. (2005), Wikis in Teaching and Assessment: The M/Cyclopedia Project. Retrieved from http://snurb.info/files/Wikis\%20in\%20Teaching\%20and\%20Assessment.pdf

Burbank, M. D., \& Kauchak, D. (2003). An alternative model for professional development: Investigations into effective collaboration. Teaching and Teacher Education, 19(5), 499-514.

Caracelli, V. J., \& Greene, J. C. (1997). Crafting mixed-method evaluation design. In J. C. Greene \& V. J. Caracelli (Eds.), Advances in mixed-method evaluation: The challenges and benefits of integrating diverse paradigms (pp. 19-32). San Francisco, CA: Jossey-Bass.

Carroll, J. M., Choo, C. W., Dunlap, D. R., Isenhour, P. L., Kerr, S. T., MacLean, A., \& Rosson, M. B. (2003). Knowledge management support for teachers. Educational Technology, Research and Development, 51(4), 42-64.

Coakes, E., \& Smith, P. A. (2007). Supporting innovation: Communities of practice and change. Journal of Knowledge Management Practice, 8(SI1). Retrieved from http://www.tlainc.com/articlsi3.htm

Cohen, D. (2009). The Impact of wiki-based collaborative environment on mathematical dialogue. Proceedings of the $4^{\text {th }}$ Chais Conference for the Study of Educational Technologies. The Open University, Raanana, Israel, 64-69. (in Hebrew)

Curry, P., Sherry, R., \& Tunney, O. (2003). What transferable skills do employers look for in third-level graduates? Results of Employer Survey. Dublin: Transferable Skills Project.

Da Lio, E., Fraboni, L., \& Leo, T. (2005). TWiki-based facilitation in a newly formed academic community of practice. Proceedings of the 2005 International Symposium on Wikis. San Diego, California, ACM Press. Retrieved from http://www.wikisym.org/ws2005/proceedings/paper-09.pdf 
Day, C., \& Leith, R. (2007). The continuing professional development of teachers: Issues of coherence, cohesion and effectiveness. In T. Townsend (Ed.), International handbook of school effectiveness and improvement (pp.707-726). Springer, The Netherlands.

Delgadillo, B. (2004). Wikis: Working their way into the Web. Retrieved from http://www.360doc.com/content/05/1206/12/1925_40614.shtml

Department for Education (2011). The national strategies. Retrieved from http://nationalstrategies.standards.desf.gov.uk/

Department of Education, Employment and Workplace Relations. (2011). Education reform agenda [Australia]. Retrieved from http://www.deewr.gov.au/schooling/Pages/Education reform agenda.aspx

Duffy, P., \& Burns, A. (2006). The use of blogs, wikis and RSS in education: A conversation of possibilities. Proceedings of the Online Learning and Teaching Conference, 2006. Brisbane. Retrieved from http://eprints.qut.edu.au/archive/00005398/.

Ebersbach, A., Glaser, M., \& Heigl, R. (2006). Wiki: web collaboration. Berlin: Springer-Verlag.

Ebner, M., \& Kickmeier-Rust, M. (2008). Utilizing Wiki systems in higher education classes: a chance for universal access? Universal Access in the Information Society, 7, 199-207.

Elgort, I., Smith, A. G., \& Toland, J. (2008). Is wiki an effective platform for group course work? Australasian Journal of Educational Technology, 24(2), 195-210.

Eshet-Alkalai, Y. (2004). Digital literacy: A conceptual framework for survival skills in the digital era. Journal of Educational Multimedia and Hypermedia, 13(1), 93-106.

Foley. B. \& Chang, T. (2006). Wiki as a professional development tool, Retrieved from http://www.csun.edu/ $\sim$ bfoley/AERA_Wiki.pdf

Goeffrey, S. (2008). Using a wiki in a community of practice to strengthen K-12 education. TechTrends, 52(6), 55-60.

Goetz, J. P., \& LeCompte, M. D. (1984). Ethnography and qualitative design in educational research. Orlando, FL: Academic Press.

Goodwin-Jones, B. (2003). Blogs and Wikis: Environments for on-line collaboration. Language, Learning \& Technology, 7(2), 12-16.

Herndon, C. (2006). Peer review and organizational learning: Improving the assessment of student learning. Research and Practice in Assessment, 1(1), 1-7.

Hill, H. C., Rowan, B., \& Ball, D. (2005). Effects of teachers' mathematical knowledge for teaching on student achievement. American Educational Research Journal, 42(2), 371-406.

Hislop, D. (2002). Mission impossible? Communicating and sharing knowledge via information technology. Journal of Information Technology, 17, 165-177.

Horizon Report (2007). 2007 Horizon Report. Retrieved from http://www.nmc.org/publications

Keig, L., \& Waggoner, M. D. (1994). Collaborative peer review: Role of faculty in improving college teaching. Washington D.C.: ERIC-ASHE.

Köhler, A., \& Fuchs-Kittowski, F. (2005). Integration of communities into process-oriented structures. Journal of Universal Computer Science, 11(3), 410-425.

Konja, M. \& Ben-Zvi, D. (2008a). The added value of wiki to collaborative learning as viewed by the learners. Proceedings of the $3^{\text {rd }}$ Chais Conference for the Study of Educational Technologies. The Open University, Raanana, Israel, 145-151. (in Hebrew)

Konja, M. \& Ben-Zvi, D. (2008b). Collaborative learning processes in Wiki-based environments in higher education. Proceedings of the $3^{\text {rd }}$ Chais Conference for the Study of Educational Technologies. The Open University, Raanana, Israel, 165-170. (in Hebrew) 
Kussmaul, C., Howe, S., \& Priest, S. (2006). Using wikis to foster team communication, cohesion, and collaboration. Journal of Computing Sciences in Colleges, 21(6), 66-68.

Lave, J., \& Wenger, E. (1991). Situated learning: Legitimate peripheral participation. Cambridge: Cambridge University Press.

Levin- Peled, R. \& Kali, Y. (2008). Using wiki to support inquiry learning in higher education. Proceedings of the $3^{\text {rd }}$ Chais Conference for the Study of Educational Technologies. The Open University, Raanana, Israel, 86-93. (in Hebrew)

Levin- Peled, R., \& Kali, Y. (2009). Using wiki to support peer instruction. Proceedings of the $4^{\text {th }}$ Chais Conference for the Study of Educational Technologies. The Open University, Raanana, Israel, 87-94. (in Hebrew)

Lund, A., \& Smørdal, O. (2006). Is there space for the teacher in a wiki? Proceedings of the 2006 International Symposium on Wikis, Odense, Denmark. Retrieved from http://portal.acm.org/citation.cfm?id=1149453.1149466

National Council of Teachers of Mathematics. (2000). Principles and standards for school mathematics. Reston, VA: NCTM.

Neuendorf, K. A. (2002). The content analysis guidebook. Thousand Oaks, CA: Sage

Owen, M., Grant, L., Sayers, S., \& Facer, K. (2006). Opening education: Social software and learning. Bristol: Futurelab. Retrieved from http://www.futurelab.org.uk/research

Pass, Y. (2009). Goals for the 2009/10-2011/12 School Years. An official letter from the general director of the Israel ministry of education sent to all high school principals. Ministry of Education, Jerusalem, Israel, June 8, 2009.

Rogers, R. K., \& Threatt, D. (2000). Peer assistance and peer review. Thrust for Educational Leadership, 29(3), 14-16.

Romberg, T. A. (1988). Can teachers be professionals? In D. A. Grouws, T. J. Cooney, \& D. Jones (Eds.), Perspectives on research on effective mathematics teaching (pp. 224-244). Reston, VA: NCTM \& Hillsdale, NJ: Erlbaum.

Schwartz, L., Clark S., Cossarin M., \& Rudolph J. (2004). Educational wikis: Features and selection criteria. The International Review of Research in Open and Distance Learning, 5(1), xxvii.

Shulman, L. S. (1987). Knowledge and teaching: Foundations of the new reform. Harvard Educational Review, 56, 1-22.

Tal, H., \& Tal, E. (2006). Wiki-Maman: A collaborative assignment in a Wiki environment. Proceedings of the $1^{\text {st }}$ Chais Conference for the Study of Educational Technologies. The Open University, Raanana, Israel, 43-54. (in Hebrew)

Tal-Elhasid, E., \& Meishar-Tal, H. (2007). Wikis in academic courses: Models of usage and collaboration. Proceedings of the $2^{\text {nd }}$ Chais Conference for the Study of Educational Technologies. The Open University, Raanana, Israel, 127-136. (in Hebrew)

Wenger, E. (1998). Communities of practice: Learning, meaning, and identity. Cambridge, UK: Cambridge University Press.

Wenger, E. (2001) Supporting communities of practice: A survey of community-oriented technologies. Report to the Council of CIOs of the US Federal Government. Retrieved from http://www.ewenger.com/tech/

Wheeler, S., Yeomans, P., \& Wheeler, D. (2008). The good, the bad and the wiki: Evaluating studentsgenerated content for collaborative learning. British Journal of Educational Technology, 39(6), 987995.

Wikipedia:About. (n.d.) In Wikipedia. Retrieved March, 2011, from http://en.wikipedia.org/wiki/Wikipedia:About 


\section{Biographies}



Atara Shriki (shriki@technion.ac.il) is a senior lecturer at Oranim Academic College of Education, in Israel. She teaches undergraduate and graduate courses in mathematics and mathematics education for pre- and in-service teachers. She is also active in various in-service programs for high school mathematics teachers. Her research interest is in teacher change through their engagement in action research.



Nitsa Movshovitz-Hadar (nitsa@technion.ac.il) is a professor emeritus of mathematics education at Technion - Israel Institute of Technology. She received her Ph.D. at U. C. Berkeley in 1975 and spent her entire career in a variety of $R \& D$ activities to improve mathematics education in Israel. She authored (with J. Webb) "One equals Zero and other mathematical surprise" - a collection of paradoxes and their pedagogical enhancements. She was the director of the Israel National Museum of Science, and nowadays she gives public lectures in mathematics and is active in the study of: Integration of values with mathematics teaching; Interweaving mathematical news snapshots in high school curriculum; The development of computer platform for collaborative accumulation of teachers' pedagogical knowledge in mathematics. 